\title{
Body mass index and lifetime healthcare utilization
}

\author{
Christina Hansen Edwards ${ }^{1^{*}}$ (D) Eline Aas $^{2}$ and Jonas Minet Kinge ${ }^{3,2}$ (D)
}

\begin{abstract}
Background: Overweight and obesity is a major global public health challenge, and understanding the implications for healthcare systems is essential for policy planning. Past studies have typically found positive associations between obesity and healthcare utilization, but these studies have not taken into consideration that obesity is also associated with early mortality. We examined associations between body mass index (BMI, reported as $\mathrm{kg} / \mathrm{m}^{2}$ ) and healthcare utilization with and without taking BMl-specific survival into consideration.

Methods: We used nationally representative data on 33882 adults collected between 2002 and 2015. We computed BMI- and age-specific primary and secondary care utilization and multiplied the estimated values with gender-, age-, and BMI-specific probabilities of surviving to each age. Then, we summed the average BMI-specific utilization between 18 and 85 years.
\end{abstract}

Results: During a survival-adjusted lifetime, males with normal weight (BMI: 18.5-24.9) had, on average, 167 primary care, and 77 secondary care contacts. In comparison, males with overweight (BMI: 25.0-29.9), category I obesity (BMI: 30.0-34.9), and category II/III obesity (BMI $\geq 35.0$ ) had 11\%, 41\%, and 102\% more primary care, and 14\%, 29\%, and $78 \%$ more secondary care contacts, respectively. Females with normal weight had, on average, 210 primary care contacts and 91 secondary care contacts. Females with overweight, category I obesity, and category II/III obesity had 20\%, 34\%, and $81 \%$ more primary care contacts, and 26\%, 16\%, and 16\% more secondary care contacts, respectively.

Conclusion: The positive association between BMI and healthcare utilization was reduced, but not offset, when BMIspecific survival was taken into consideration. Our findings underpin previous research and suggest that interventions to offset the increasing prevalence of overweight, and especially obesity, are warranted.

Keywords: Body mass index, Obesity, Health services, Mortality, Public Policy

\section{Background}

Compared with individuals with normal weight, persons with obesity have a greater likelihood of acquiring a range of serious diseases: type-2 diabetes, cardiovascular disease, gallbladder disease, osteoarthritis, hypertension, kidney disease, dyslipidaemia and several cancers [1-3]. Hence, increased healthcare utilization may be needed to manage these conditions. However, in the context of obesity, early mortality may counterbalance increased healthcare utilization due to morbidity. Existing studies that have investigated associations between obesity and healthcare utilization have been done from a nonlifetime perspective, without consideration of early

\footnotetext{
* Correspondence: christina.hansen.edwards@fhi.no

${ }^{1}$ Centre for Fertility and Health, Norwegian Institute of Public Health,

Folkehelseinstituttet, Postboks 222 Skøyen, 0213 Oslo, Norway

Full list of author information is available at the end of the article
}

mortality [4]. As a result, it remains unclear whether healthcare utilization over a cumulative lifetime is higher among persons with obesity, compared with persons with normal weight.

Non-lifetime studies have found associations between obesity and physician encounters [5-11], hospitalizations $[7,8,12]$, and hospital outpatient visits $[6,7,12]$, and specialist visits [9]. A few studies have not found significant associations between obesity and hospitalization $[5,6,11]$ or find differing results depending on age [13], or gender [10]. These previous studies vary in terms of methodology, the number of obesity categories assessed, types of healthcare providers included, and the organization of the healthcare system under study. In addition, several of these studies have focused on a specific sub-population

(c) The Author(s). 2019 Open Access This article is distributed under the terms of the Creative Commons Attribution 4.0 International License (http://creativecommons.org/licenses/by/4.0/), which permits unrestricted use, distribution, and 
(typically females or elderly), rather than a whole population.

The objective of this study was to estimate associations between BMI and utilization of primary and secondary care services from a lifetime cumulative perspective with and without consideration of BMI-specific survival. A few studies have assessed lifetime healthcare costs associated with obesity [14-19] and these studies maintain that obesity is associated with increased healthcare costs, but no studies have assessed lifetime healthcare utilization. The studies evaluating lifetime costs are based on data from the United States, and therefore the findings may not be transferable to settings with a dissimilar healthcare system. Our study was based on data from Norway where the healthcare system is mainly publicly funded, and access to healthcare is universal. As in most countries worldwide, obesity is a major public health challenge in Norway. The proportion of adult obesity has been estimated at 19\% among females and 20\% among males [20]. In comparison, globally, an estimated $15 \%$ of female, and $11 \%$ of male adults have obesity [21]. This study contributes to the literature as it is the first to: estimate the effect of obesity on lifetime healthcare utilization, gauge the effect of BMIspecific survival on BMI-specific healthcare utilization, and to use data from a publicly funded healthcare system to assess BMI-specific lifetime healthcare utilization. This study is also the first to estimate BMI-specific healthcare utilization in Norway.

\section{Methods}

To estimate BMI-specific utilization of primary and secondary care services over a lifetime, we computed BMI-, age-, and gender- specific survival probabilities. We then estimated BMI- and gender-specific primary and secondary healthcare utilization from an adult lifetime perspective with and without consideration of survival effects.

\section{Sample}

We used data from the Level of Living Surveys, which are cross-sectional surveys conducted yearly by Statistics Norway. These surveys are intended to provide information about the living conditions of different social groups in Norway. The surveys rotate between three themes: working conditions, living conditions, and health. For this study used the five most recent health-themed studies. These were conducted during the periods 20022003, 2005-2006, 2008-2009, 2012-2013 and 2015. The sample populations were selected via stratified random sampling of persons in Norway aged 16 years and above, and are considered to be largely nationally representative. For surveys conducted during the periods 2002-2003, 2005-2006, 2008-2009, and 2012-2013, initial data collection was done via personal face-to-face or telephone interviews. The response rates for these initial interviews were
$70 \%, 70 \%, 67 \%$, and $58 \%$, respectively. All subjects that had been invited to participate in interviews were later invited to reply to a postal or web-based questionnaire, for which the response rates were $64 \%, 57 \%, 50 \%$, and $71 \%$, respectively. In 2015, the survey was conducted via computerassisted telephone interviews, and no questionnaires were sent. The overall response rate for 2015 was 59\%.

The sampling omits individuals in: retirement homes, orphanages, nursing homes, psychiatric institutions, institutions for intellectually disabled, and institutions for drug and alcohol abusers. Detailed information about the sampling procedures and sample representability for each of the study samples have been published in comprehensive reports [22-26]. Data gathered from the surveys had also been linked, using personal ID-numbers, with national registry data on sociodemographic variables such as education and income.

Our dataset was comprised of 33882 individual-level observations, and included information about healthcare utilization, self-reported height and weight and a range of background variables, including: gender, age, educational level, marital status, smoking status, geographical region of residence, household size, and household income. When reporting weight, pregnant women were asked to provide their pre-pregnancy weight. In terms of healthcare utilization, we used the reported number of primary care contacts, hospital outpatient visits, specialist visits outside of hospital, and hospital inpatient overnight stays; in the past 12 months. For hospital overnight stays, we excluded contacts related to child delivery. In our analyses we combined specialist visits and hospital outpatient and inpatient visits to create a broader outcome category for secondary care. Our data contained information on primary care utilization for all study years and secondary care utilization in 2008-2009, 2012-2013, and 2015.

\section{BMI computation and classification}

We computed the BMI (mass (kg)/ height $(\mathrm{m})^{2}$ ) of each respondent, and classified each measure according to the World Health Organization's standard categories: underweight $(\mathrm{BMI}<18.5)$, normal weight (BMI $\geq 18.5$ and $<25$ ), overweight (BMI $\geq 25$ and $<30$ ), category I obesity (BMI $\geq 30$ and $<35$ ), and category II/ III obesity (a BMI $\geq 35$ ). To avoid potential bias from response errors we excluded all cases with a $\mathrm{BMI}<11$ and cases with a $\mathrm{BMI} \geq 90$.

\section{Calculating BMI-specific survival}

BMI-specific survival was estimated by combining gender- and BMI-specific hazard ratios for all-cause mortality, recently estimated by Kjøllesdal and coworkers [27] with national life tables for the Norwegian population in 2015 [28]. To compute these 
hazard ratios, individuals with BMI measured in early adulthood (18-20 years of age) and in midlife (40-50 years of age) had been followed up until death. If death had not incurred during the followup period, individuals were censored at their age at the end of follow-up. The estimated hazard ratios had been adjusted for education and cardiovascular risk factors (smoking, serum total cholesterol, systolic and diastolic blood pressure, current treatment for hypertension, heart rate and height).

We adapted the hazard ratios to match the proportions of male and female respondents in each BMIcategory in our study sample. This was done by multiplying the proportion in each BMI-category in our study sample with the corresponding hazard ratios reported for each BMI-category. For ages 18-29 we applied the hazard ratio estimates based on BMI measured in early adulthood, and for ages 30-85 years we applied the hazard ratios based on BMI measured in midlife. We then computed a mean hazard ratio adjusted for our study sample by summing the calculated products for each BMI-category. Next, we generated BMI specific hazard ratios by dividing the reported BMI-specific hazard ratios by the mean hazard ratio for each BMI-category estimated for our study sample. Finally, we used life tables to generate one-year age-specific survival probabilities (Fig. 1, Additional file 1: Table S1 and Table S2) for males and females in each BMI-category. This was done by multiplying the probability of dying at each age by the BMI-specific adjusted hazard ratios.

\section{Regression models}

\section{Dependent and independent variables}

BMI-specific healthcare utilization was estimated from two perspectives: a lifetime cumulative perspective, and an annual perspective. In our analyses the dependent variables assessed were: primary care utilization and secondary care utilization, and the independent variables included in the models were: BMI-categories, gender, age (continuous), age ${ }^{2}$, study period (categorical), educational level (categorical), marital status (categorical), geographical region of residence (categorical), and smoking status (categorical). In all our models, we included underweight as a BMI-category, but since the focus of our paper is on overweight and obesity, we do not discuss findings related to underweight. For further information about the variables and categories see Table $1 .{ }^{1}$ We performed our analyses with and without gender

\footnotetext{
${ }^{1}$ We explored the inclusion of sample weights (based on gender, 5 -year age-groups, four education levels, and seven geographical regions), but this did not make a significant difference to the results. As a result we left the weights out to ease the interpretation of our findings.
}

stratification, and in the model without stratification, gender was included as a covariate in the model.

\section{Annual perspective analyses}

For each healthcare utilization outcome we had information about whether or not a contact had taken place, and the frequency of contacts. The distributions of our dependent variables were overdispersed and a variety of regression models are available for such situations [29]. For each healthcare utilization outcome, we used Akaike's information criterion (AIC) to compare: negative binomial models, zero-inflated Poisson models, zero-inflated negative binomial models, logit-Poisson hurdle models, probit-Poisson hurdle models, logitnegative binomial hurdle models, and probit-negative binomial hurdle models. The models with the lowest AIC were selected, and for each outcome the logit-negative binomial hurdle model outperformed the other model variants.

Two-part hurdle models have frequently been used to analyse healthcare utilization [30, 31]. These models regard healthcare utilization as a two-stage process. In our analyses, the first stage of the model, referring to a consumers' decision to seek healthcare, was modelled as a binary process estimated using a logit model. The second stage is only applied (i.e. the hurdle is only crossed) for those with a positive healthcare utilization. In the second stage, the frequency of contact was modelled using a truncated-at-zero negative binomial model. The advantage of differentiating between the decision to seek healthcare and the frequency of healthcare utilization, is that these processes may be affected by different factors [30]. For instance, a person's decision to seek healthcare is likely to be influenced by the patients' subjective need for and ability to seek care. The frequency of consultations, however, might for instance be influenced by the physician and guidelines.

The hurdle regressions were done using the methods described by Deb, Norton, and Manning [32]. Results from the first part of the hurdle model were reported as odds ratios (ORs), and results from the second part of the hurdle model were reported as incidence rate ratios (IRRs). We also report the average expected yearly utilization of primary and secondary care services, for each BMI-category by gender. Regressions were performed in Stata 15 [33] and further analyses were done in $\mathrm{R}$ version 3.3.1 [34].

\section{Lifetime cumulative perspective analyses}

To calculate lifetime utilization with and without survival adjustment, we adapted the method used by Finkelstein and co-workers to estimate lifetime medical costs of obesity [19]. Our lifetime analysis included persons aged 18-85 years. This age restriction was applied for 

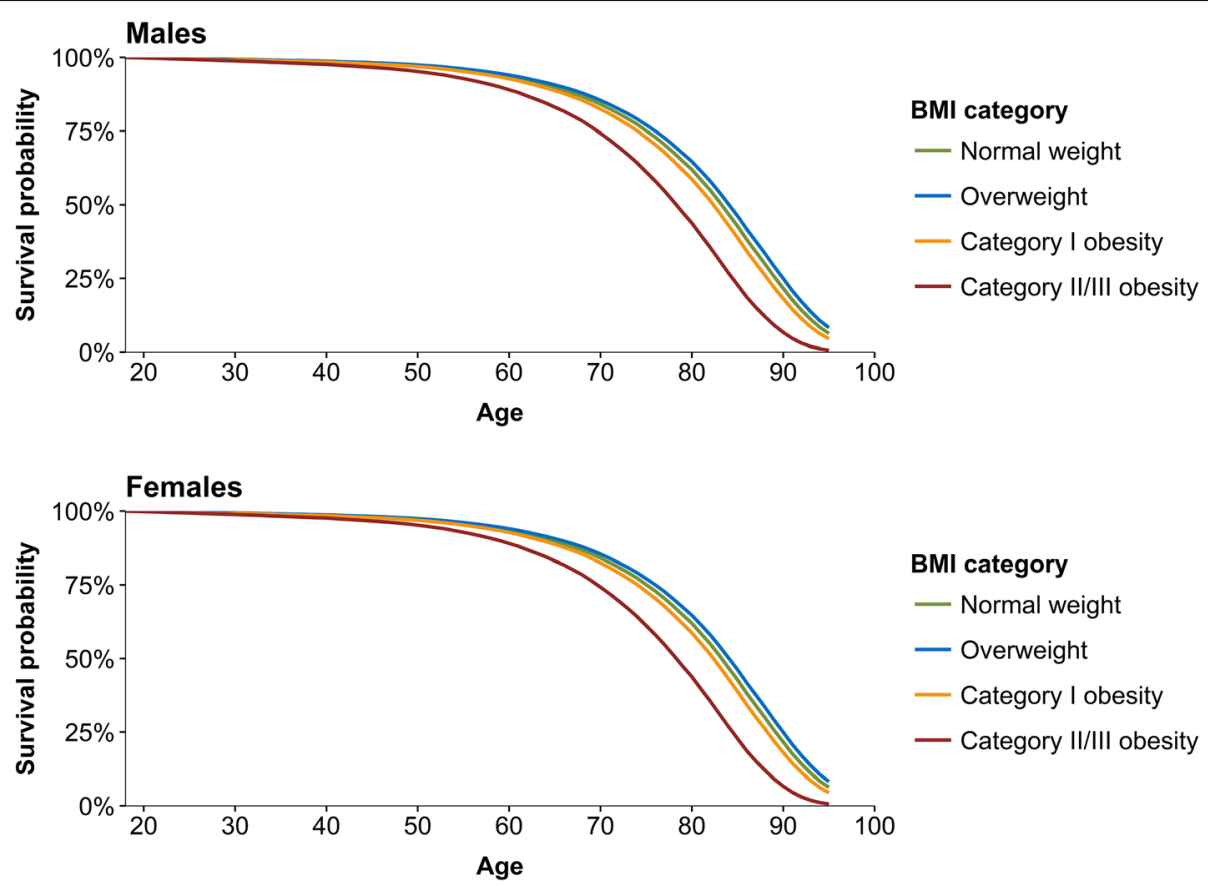

Fig. 1 Estimated survival probabilities by age, BMI, and gender

the lifetime analyses because our data did not contain information about individuals in nursing- and retirement homes. To allow for more flexibility in our age-specific estimations, we adapted our hurdle model to include cubic-restricted age-splines with knots at five percentile locations (5\%, 27.5\%, 50\%, 72.5\%, and 95\%). For each one-year age group we computed BMI-specific average healthcare utilization, while accounting for the agespecific covariate means. This method was applied because some covariate categories would be unrealistic at some ages, and therefore computing age-specific utilization with covariates at the population mean could bias our findings. For instance, in the youngest age groups the probability of being a widow/widower or divorced/separated would be smaller than for an older adult. In the analysis that considered BMI-specific survival, we multiplied the average age- and BMI-specific healthcare utilization with the estimated probabilities of surviving to each age.

Next, we summed the average utilization at each age to obtain a lifetime cumulative utilization estimate. The 95\% confidence intervals were calculated using a bootstrap resampling procedure with 500 iterations. The results of the lifetime cumulative perspective analysis can be interpreted as the average expected utilization of primary care services for an 18-year-old, given that he or she remained in the same BMI-category throughout adulthood, and assuming that future healthcare utilization is similar to current utilization.

\section{Results}

In total 676 (2\%) of the 33882 responses in the original dataset were excluded from our analysis. Responses were omitted either because BMI was missing $(\mathrm{N}=672)$, or because the calculated BMI was outside our BMI cut-offs $(\mathrm{BMI}<11(\mathrm{~N}=1)$ and $\mathrm{BMI}>90(\mathrm{~N}=2))$. Our final dataset contained information about sociodemographic factors and healthcare utilization (Table 1), for 33206 respondents. The proportion of male and female respondents was similar, and respondents had an average age of 46.5 years (range: 16-101 years) (Table 1). The average BMI of the respondents was $25.0 \mathrm{~kg} / \mathrm{m}^{2}$ (range: $11.7-85.7 \mathrm{~kg} /$ $\mathrm{m}^{2}$ ), and in total $45 \%$ of respondents had overweight or obesity. The proportion of respondents with overweight increased from $43 \%$ in 2002 to $49 \%$ in 2015 , and in the same period the proportion of respondents with obesity increased from $8 \%$ to 13 .

In the sample, the mean number of primary care contacts was $2.9(\mathrm{SD}=4.8)$ for males, and $3.8(\mathrm{SD}=5.2)$ for females, and the mean number of secondary care contacts was $1.3(\mathrm{SD}=4.0)$ for males, and 1.6 $(\mathrm{SD}=4.5)$ for females. The crude average number of contacts reported increased with increasing BMI (Table 2).

\section{Healthcare utilization (annual perspective) Primary care utilization}

Compared with persons with normal weight, individuals with overweight and obesity had a significantly $(\mathrm{p}<0.01)$ higher probability of primary care contact, and, given 
Table 1 Sociodemographic characteristics of the study sample, by gender and BMI-category, numbers (\%) ${ }^{a}$

\begin{tabular}{|c|c|c|c|c|c|c|c|c|c|}
\hline & & \multicolumn{4}{|l|}{ Male } & \multicolumn{4}{|l|}{ Female } \\
\hline & & $\begin{array}{l}\text { Normal } \\
\text { weight }\end{array}$ & Overweight & $\begin{array}{l}\text { Category I } \\
\text { Obesity }\end{array}$ & $\begin{array}{l}\text { Category II/ } \\
\text { III Obesity }\end{array}$ & $\begin{array}{l}\text { Normal } \\
\text { weight }\end{array}$ & Overweight & $\begin{array}{l}\text { Category I } \\
\text { Obesity }\end{array}$ & $\begin{array}{l}\text { Category II/ } \\
\text { III Obesity }\end{array}$ \\
\hline & & $(n=7595)$ & $(n=7211)$ & $(n=1516)$ & $(n=305)$ & $(n=9810)$ & $(n=4566)$ & $(n=1206)$ & $(n=326)$ \\
\hline \multirow[t]{5}{*}{ Age } & $16-24$ & $1693(22)$ & $506(7)$ & $86(6)$ & $19(6)$ & $1671(17)$ & $325(7)$ & $68(6)$ & $17(5)$ \\
\hline & $25-44$ & 2498 (33) & $2453(34)$ & $551(36)$ & $125(41)$ & $3546(36)$ & $1348(30)$ & $359(30)$ & $125(38)$ \\
\hline & $45-66$ & $2270(30)$ & $3131(43)$ & $678(45)$ & $128(42)$ & 3237 (33) & $1948(43)$ & $530(44)$ & $139(43)$ \\
\hline & $67-79$ & $823(11)$ & $915(13)$ & $181(12)$ & $30(10)$ & $953(8)$ & $702(15)$ & $208(17)$ & $29(9)$ \\
\hline & $80+$ & $311(4)$ & $206(3)$ & $20(1)$ & $3(1)$ & $403(4)$ & $243(5)$ & $41(3)$ & $16(5)$ \\
\hline \multirow[t]{4}{*}{ Marital status } & Unmarried & $3600(47)$ & $2327(32)$ & $485(32)$ & $139(46)$ & 3773 (38) & $1191(26)$ & $334(28)$ & $94(29)$ \\
\hline & Married & $3278(43)$ & $4183(58)$ & $872(58)$ & $144(47)$ & $4463(46)$ & $2472(54)$ & $604(50)$ & $169(52)$ \\
\hline & Widow/ widower & $198(3)$ & $167(2)$ & $38(3)$ & $6(2)$ & $658(7)$ & $439(10)$ & $145(12)$ & $26(8)$ \\
\hline & Divorced/ separated & $517(7)$ & $533(7)$ & $120(8)$ & $16(5)$ & $913(9)$ & $464(10)$ & $123(10)$ & $37(11)$ \\
\hline \multirow[t]{4}{*}{ Education } & $<$ Upper secondary & $1528(21)$ & $1249(18)$ & $305(21)$ & $81(27)$ & 1806 (19) & $978(22)$ & $291(25)$ & $81(25)$ \\
\hline & Upper secondary & $3488(49)$ & $3815(54)$ & $842(57)$ & $151(51)$ & $4136(44)$ & $2109(47)$ & $547(46)$ & $165(51)$ \\
\hline & Higher educ. (short) & $1376(19)$ & $1386(20)$ & $252(17)$ & $50(17)$ & $2778(30)$ & $1191(27)$ & $304(26)$ & $67(21)$ \\
\hline & Higher educ. (long) & $775(11)$ & $612(9)$ & $81(5)$ & $16(5)$ & $65(7)$ & $189(4)$ & $39(3)$ & $8(2)$ \\
\hline \multirow[t]{4}{*}{ Geographic region } & East & $3675(48)$ & $3320(46)$ & $704(46)$ & $148(49)$ & $4939(50)$ & $2176(48)$ & $555(46)$ & $151(46)$ \\
\hline & West & $1300(17)$ & $1241(17)$ & $256(17)$ & $37(12)$ & $1609(16)$ & $754(17)$ & $201(17)$ & $49(15)$ \\
\hline & South & $1073(14)$ & $1075(15)$ & $210(14)$ & $46(15)$ & $1393(14)$ & $607(13)$ & $163(14)$ & $47(14)$ \\
\hline & Mid \& North & $1547(20)$ & $1575(22)$ & $346(23)$ & $74(24)$ & $1869(19)$ & $1029(23)$ & $287(24)$ & $79(24)$ \\
\hline \multirow[t]{3}{*}{ Smoking status } & Daily & $1669(25)$ & $1541(24)$ & $291(22)$ & $67(24)$ & $2006(23)$ & $945(23)$ & $251(23)$ & $62(21)$ \\
\hline & Occasionally & $773(12)$ & $638(10)$ & $138(10)$ & $19(7)$ & $977(11)$ & $406(10)$ & $67(6)$ & $21(7)$ \\
\hline & Non-smoker & $4293(64)$ & $4333(67)$ & $915(68)$ & $188(69)$ & $5731(66)$ & $2742(67)$ & 778 (71) & $206(71)$ \\
\hline \multirow[t]{5}{*}{ Study period } & Years 2002-2003 & 1655 (22) & $1415(20)$ & $242(16)$ & $43(14)$ & $2061(21)$ & $878(19)$ & $219(18)$ & $45(14)$ \\
\hline & Years 2005-2006 & $1571(21)$ & $1466(20)$ & $266(18)$ & $52(17)$ & $2005(20)$ & $891(20)$ & $207(17)$ & $63(19)$ \\
\hline & Years 2008-2009 & 1398 (18) & 1372 (19) & $297(20)$ & $53(17)$ & 1915 (20) & $872(19)$ & $216(18)$ & $58(18)$ \\
\hline & Years 2012-2013 & $1266(17)$ & $1190(17)$ & $268(18)$ & $47(15)$ & $1626(17)$ & 805 (18) & $193(16)$ & $54(17)$ \\
\hline & Years 2015-2016 & 1705 (22) & 1768 (25) & 443 (29) & $110(36)$ & $2203(22)$ & $1120(25)$ & $371(31)$ & $106(33)$ \\
\hline
\end{tabular}

${ }^{\mathrm{a}}$ Missing data were not included in the calculation of percentages

that contact had been made, had a significantly $(\mathrm{p}<0.01)$ greater number of contacts per year (Additional file 1 : Table S3). Increased primary care utilization was seen for males and females with overweight and obesity (Additional file 1: Table S4 and Table S5). Compared with respondents with normal weight, respondents with overweight, category I obesity, and category II/III obesity made, on average, $12 \%, 34 \%$, and $91 \%$ more contacts per year, respectively (Table 3 ).

\section{Secondary care utilization}

Compared with respondents with normal weight, respondents with overweight and obesity had a significantly $(p<0.01)$ higher likelihood of secondary care contact, and respondents with category II/III obesity were more likely to have had a significantly $(\mathrm{p}<0.01)$ greater number of contacts (Additional file 1: Table S6). A similar pattern of secondary care utilization was seen for both males and females with overweight and obesity (Additional file 1: Table S7 and S8). The only exception was that females with category II/III obesity were not found to have a higher likelihood of contact, compared with normal weight females. Compared with respondents with normal weight, respondents with overweight, category I obesity, and category II/III obesity made, on average, $13 \%, 21 \%$, and $51 \%$ more contacts per year, respectively (Table 3).

\section{Lifetime cumulative healthcare utilization Primary care utilization}

Accounting for survival reduced the mean predicted lifetime cumulative primary care utilization by $12 \%-17 \%$ for males and by $10 \%-16 \%$ for females (Table 4, Fig. 2).

After considering survival, males with overweight, category I obesity, and category II/III obesity made contact with a primary care provider on average $11 \%, 41 \%$, and 
Table 2 Crude mean (SD) number of primary and secondary care contacts per year, by BMl-category and gender

\begin{tabular}{|c|c|c|c|c|}
\hline & Normal weight & Overweight & Category I obesity & Category II/III obesity \\
\hline \multicolumn{5}{|c|}{ Mean number of primary care contacts (SD) } \\
\hline All & $3.1(4.5)$ & $3.4(4.9)$ & $4.2(5.8)$ & $6.1(8.9)$ \\
\hline Male & $2.6(4.3)$ & $2.9(4.8)$ & $3.8(6.2)$ & $5.5(6.2)$ \\
\hline Female & $3.4(4.6)$ & $4.1(5.0)$ & $4.7(5.1)$ & $6.7(10.7)$ \\
\hline \multicolumn{5}{|c|}{ Mean number of secondary care contacts (SD) } \\
\hline All & $1.4(4.0)$ & $1.5(4.4)$ & $1.7(4.2)$ & $2.0(3.9)$ \\
\hline Male & $1.2(3.8)$ & $1.6(3.9)$ & $1.7(4.8)$ & $1.9(3.6)$ \\
\hline Female & $1.5(4.1)$ & $1.7(5.1)$ & $1.7(3.2)$ & $2.1(4.1)$ \\
\hline
\end{tabular}

$102 \%$ more often than males with normal weight, respectively (Table 4). Females with overweight, category I obesity, and category II/III obesity made contact with a primary care provider, on average, $20 \%, 34 \%$, and $81 \%$ more often compared with females with normal weight, respectively (Table 4). The confidence intervals suggest that both before and after taking survival into consideration, males and females with overweight and obesity had a significantly higher primary care utilization, compared with their normal weight counterparts.

\section{Secondary care utilization}

Accounting for survival reduced the mean predicted lifetime cumulative secondary care utilization by $13 \%-17 \%$ for males and 11\%-15\% for females (Table 5, Fig. 2).

After accounting for survival, males with overweight, category I obesity, and category II/III obesity made, on average, $14 \%, 29 \%$, and $78 \%$ (Table 5) more contacts than normal weight males, respectively. Females with overweight, category I obesity, and category II/III obesity made, on average, $16 \%, 16 \%$, and $26 \%$ (Table 5) more contacts than normal weight females. After taking survival into consideration there was overlap between the confidence intervals of nearly all the BMI-categories within each gender strata. The only exception was that the confidence intervals of males with category II/III obesity and normal weight did not overlap.

\section{Discussion}

The study has quantified the BMI-specific consequences of overlooking survival-adjustment when estimating the association between BMI and healthcare utilization. After consideration of survival, we found a positive association between overweight and obesity and primary care utilization in both males and females; secondary care utilization was only found to be significantly higher for males with category II/III obesity, compared with normal weight males. Nevertheless, there was a tendency for secondary care utilization to increase with BMI. Our estimates suggest that during a lifetime, an 18-year-old male with a $\mathrm{BMI} \geq 35$, can be expected to make 171 (102\%) more primary care, and 60 (78\%) more secondary care contacts, compared with a normal weight male. An 18 -year old female with a $\mathrm{BMI} \geq 35$ can be expected to make 170 (81\%) more primary care, and 24 (26\%) more secondary care contacts, compared with a normal weight female.

Studies that have assessed associations between excess BMI and healthcare utilization without a lifetime perspective have typically found positive associations between obesity and primary care utilization [5-11]. These findings correspond well with the results from our annual perspective analyses. For both males and females we found positive associations between overweight and obesity and the likelihood of primary care utilization. Most previous studies $[6-9,12]$ have found positive

Table 3 Predicted mean $(95 \%$ Cl) number of primary and secondary care contacts per year, by BMl-category and gender.

\begin{tabular}{|c|c|c|c|c|}
\hline & Normal weight & Overweight & Category I obesity & Category II/III obesity \\
\hline \multicolumn{5}{|c|}{ Mean number of primary care contacts $(95 \% \mathrm{Cl})$} \\
\hline All & $3.3(3.2 ; 3.4)$ & $3.7(3.6 ; 3.8)$ & $4.5(4.2 ; 4.7)$ & $6.3(5.6 ; 7.1)$ \\
\hline Male & $2.9(2.8 ; 3.0)$ & $3.2(3.0 ; 3.3)$ & $4.0(3.7 ; 4.4)$ & $5.9(5.1 ; 6.7)$ \\
\hline Female & $3.7(3.6 ; 3.8)$ & $4.4(4.2 ; 4.5)$ & $4.8(4.5 ; 5.1)$ & $6.8(5.6 ; 8.1)$ \\
\hline \multicolumn{5}{|c|}{ Mean number of secondary care contacts ( $95 \%$ Cl) } \\
\hline All & $1.4(1.2 ; 1.5)$ & $1.5(1.4 ; 1.7)$ & $1.6(1.4 ; 1.9)$ & $2.1(1.7 ; 2.5)$ \\
\hline Male & $1.2(1.1 ; 1.4)$ & $1.4(1.2 ; 1.5)$ & $1.6(1.3 ; 1.8)$ & $2.2(1.6 ; 2.9)$ \\
\hline Female & $1.5(1.3 ; 1.6)$ & $1.7(1.5 ; 1.8)$ & $1.7(1.4 ; 1.9)$ & $1.9(1.5 ; 2.4)$ \\
\hline
\end{tabular}

Estimates were adjusted for age, education marital status, geographic region of residence, smoking status and study period 
Table 4 Predicted mean $(95 \% \mathrm{Cl})$ number of primary care contacts over a lifetime, by BMI-category and gender

\begin{tabular}{lllll}
\hline Gender & BMl-category & Mean $(95 \%$ Cl) without survival & Mean $(95 \%$ Cl) with survival & Mean (\%) reduction due to survival \\
\hline Male & Normal weight & $193(185 ; 201)$ & $167(160 ; 173)$ & $26(13 \%)$ \\
& Overweight & $211(202 ; 221)$ & $185(178 ; 193)$ & $26(12 \%)$ \\
& Category I obesity & $272(249 ; 296)$ & $235(216 ; 254)$ & $37(14 \%)$ \\
& Category II/III obesity & $406(348 ; 464)$ & $338(289 ; 387)$ & $26(11 \%)$ \\
Female & Normal weight & $236(229 ; 244)$ & $210(204 ; 216)$ & $28(10 \%)$ \\
& Overweight & $281(270 ; 293)$ & $253(244 ; 264)$ & $35(11 \%)$ \\
& Category I obesity & $317(295 ; 338)$ & $282(264 ; 301)$ & $70(16 \%)$ \\
\hline
\end{tabular}

Estimates were adjusted for age, education marital status, geographic region of residence, smoking status and study period. The lifetime utilization was estimates based on participants between 18 and 85 years of age

associations between obesity and secondary care utilization, but a few do not find such an association $[5,11]$. Our results for secondary care utilization are varied, and differ between males and females.

The present study was the first to compute healthcare utilization for different BMI-categories over a lifetime and was the first to consider the effect of BMI-specific survival on healthcare utilization. Our study also had some further advantages: I) We estimated healthcare utilization associated with obesity in a public healthcare setting II) we used a nationally representative sample of male and female adults; III) we examined differences in primary and secondary care utilization between respondents with normal weight and three different categories

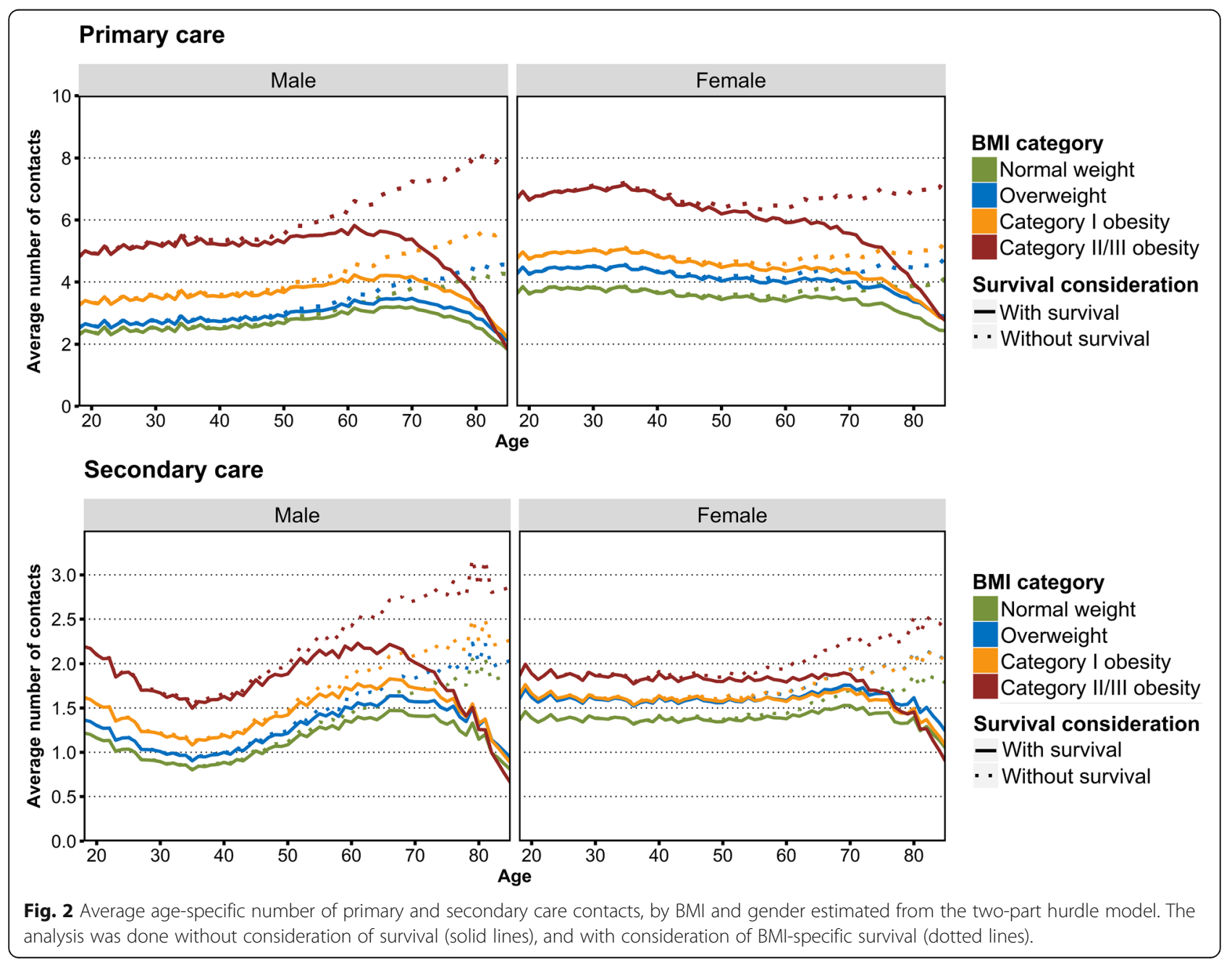


Table 5 Predicted mean (with 95\% confidence intervals) number of secondary care contacts over a lifetime, by BMI-category and

\begin{tabular}{lllll}
\hline Gender & & & \\
\hline Male & BMl-category & Mean $(95 \% \mathrm{Cl})$ without survival & Mean $(95 \%$ Cl) with survival & Mean (\%) reduction due to survival \\
& Overweight & $92(82 ; 103)$ & $77(69 ; 86)$ & $15(16 \%)$ \\
& Category I obesity & $101(91 ; 112)$ & $88(79 ; 98)$ & $13(13 \%)$ \\
& Category II/III obesity & $166(112 ; 219)$ & $99(81 ; 117)$ & $29(17 \%)$ \\
Female & Normal weight & $103(94 ; 113)$ & $137(94 ; 180)$ & $12(12 \%)$ \\
& Overweight & $119(105 ; 133)$ & $91(84 ; 98)$ & $13(11 \%)$ \\
& Category I obesity & $119(101 ; 136)$ & $106(94 ; 117)$ & $13(11 \%)$
\end{tabular}

Estimates were adjusted for age, education marital status, geographic region of residence, smoking status and study period. The lifetime utilization was estimates based on participants between 18 and 85 years of age

related to excess BMI (overweight, and category I and II/III obesity). Moreover, the survey response rate was reasonably high, with yearly response rates varying from $50-71 \%$.

This study had some limitations. First, although sampling for this study was undertaken strategically to select a sample that can be considered representative of the population, any questionnaire-based study may be subject to selection bias. For instance, a potential problem was that persons in nursing homes and persons above 85 years of age were not included in the sample. This could be problematic as these groups of individuals may have different healthcare seeking behaviour compared with the rest of the population. Also, since obesity is associated with a shorter life expectancy, we may have captured a smaller proportion of lifetime costs for persons with normal weight, than for persons with obesity. Second, respondents reported healthcare utilization during the past year, and responses may have been subject to recall bias. Third, with the exception of the data that was registry-based (such as data on income and education), data were self-reported and may have been subject to response bias. In particular, self-reported height and weight measures tend to result in an underestimation of true BMI; the extent of bias differs between sexes, and increases with age $[35,36]$. Errors in self-reported healthcare utilization data have been shown to increase with the number of healthcare encounters experienced [37]. Also, using self-reported data on healthcare utilization is likely to lead to an exclusion of end-of-life utilization. Fourth, BMI is known to be an imperfect measure of adiposity. Ideally, hip and waist measurements or other body composition measurements should supplement BMI measures, but such data were not available. Fifth, although hurdle models have been shown to be superior in settings in which general practitioners act as gatekeepers to specialist care [38], hurdle models have been criticized for not allowing distinction between high and low frequency users of healthcare [39]. Lastly, our lifetime utilization estimates do not take into account that an 18-year-old with a particular BMI may change BMI-category over a lifetime. However, a review by Simmonds et al. found that $80 \%$ of persons with adolescent obesity will have obesity in adulthood [40].

Population BMI is increasing, and although some studies have found indications that BMI has been increasing at a slower rate [41], predictions suggest that the proportion of the population with obesity is likely to continue to rise [42]. If the effects of increased BMI on healthcare utilization described in this study are in fact causal, increasing youth obesity is likely to result in increased healthcare costs in the future. In the short term, efficient planning to tackle increased demands for healthcare is warranted to reduce future economic and organizational burdens on the healthcare system. At the same time, it is essential to identify and implement effective interventions to prevent overweight, and especially obesity. In the long-run, as more data become available and new methods develop, it will be important to differentiate between obesity-related and obesity-caused drivers of healthcare utilization and costs, and to implement appropriate prevention strategies accordingly.

Our associations cannot be interpreted as causal, because our results are likely biased due to omitted variables (such as lifestyle factors [43], genetic factors [44], and time lived with overweight or obesity [45]), measurement error in covariates, and reverse causality. Despite these issues, it seems plausible that there is a positive causal association between obesity and healthcare utilization, however the amount and type of healthcare utilization owing specifically to obesity is difficult to ascertain. To reduce bias, a randomized study would be needed, but randomization in this context would be problematic. Future studies may want to explore the application of genetic information in instrumental variable analyses [46] as a way of reducing bias. Moreover, since treatment for a particular disease may depend on BMI, future studies should explore disease-specific healthcare 
utilization by BMI. Finally, this study suggests that healthcare utilization increases with BMI, and the implications of this increased demand on patients and providers should be investigated.

\section{Conclusion}

The effect of excess BMI on healthcare utilization was reduced, but not completely offset, when BMI-specific survival was taken into consideration. Future studies should attempt to account for BMI-specific survival when assessing the health and/or economic consequences of obesity. As the BMI of populations worldwide continues to rise, it is becoming increasingly important to understand the consequences. In this study, both overweight and obesity, but especially obesity, was associated with increased utilization of healthcare. As a result, healthcare payers and providers are likely to benefit from the implementation of interventions to combat obesity.

\section{Supplementary information}

Supplementary information accompanies this paper at https://doi.org/10. 1186/s12913-019-4577-0.

Additional file 1. Body mass index and lifetime healthcare utilization. Additional information. This file contains the estimated BMI-and one-year age-specific survival probabilities for males (Table S1.) and females

(Table S2.) As well as results from the hurdle regressions estimating the likelihood and frequency of primary care (Tables S3 - S5.) and secondary care (Tables S6 - S8.) contacts, for both males and females, and stratified by gender.

\section{Abbreviations}

AIC: Akaike's information criterion; BMI: Body mass index; IRR: Incidence rate ratios; OR: Odds ratio

\section{Acknowledgements}

Not applicable.

\section{Authors' contributions}

$\mathrm{CHE}, \mathrm{JMK}$, and EA contributed to the design of the study. Data analysis was done by $\mathrm{CHE}$, and interpretation of study findings was done by CME, JMK and EA. The manuscript was written by $\mathrm{CHE}$ and $\mathrm{JMK}$, and revised by $\mathrm{CHE}$, JMK, and EA. All authors have seen and approved the final version of the manuscript.

\section{Funding}

This research project was funded by the Norwegian Research Council; Grant number: 250335/F20. The funding body had no role in study design, in collection, interpretation or analysis of the data, in writing the manuscript, or in the decision to submit the manuscript for publication.

\section{Availability of data and materials}

The data that support the findings of this study are available from the Norwegian Centre for Research Data (NSD), but restrictions apply to the availability of these data, which were used under license for the current study, and so are not publicly available.

\section{Ethics approval and consent to participate}

The project data did not contain personally identifiable data and was therefore not subject to notification.

\section{Consent for publication}

Not applicable.

\section{Competing interests}

The authors declare that they have no competing interests.

\section{Author details}

${ }^{1}$ Centre for Fertility and Health, Norwegian Institute of Public Health, Folkehelseinstituttet, Postboks 222 Skøyen, 0213 Oslo, Norway. ${ }^{2}$ Department of Health Management and Health Economics, Institute of Health and Society, University of Oslo, Postboks 1089, Blindern, 0317 Oslo, Norway. ${ }^{3}$ Centre for Fertility and Health \& Centre for Disease Burden, Norwegian Institute of Public Health, Oslo, Norway.

Received: 8 July 2019 Accepted: 30 September 2019

Published online: 15 October 2019

\section{References}

1. International Agency for Research on Cancer (IARC). In., vol. Vol. 6: Weight Control and Physican Activity. Lyon, France; 2002.

2. World Health Organization. Obesity and overweight. Fact Sheet. http:// www.who.int.

3. Must A, Spadano J, Coakley EH, Field AE, Colditz G, Dietz WH. The disease burden associated with overweight and obesity. Jama. 1999;282(16):1523-9.

4. Aune D, Sen A, Prasad M, Norat T, Janszky I, Tonstad S, Romundstad P, Vatten LJ. BMI and all cause mortality: systematic review and non-linear dose-response meta-analysis of 230 cohort studies with 3.74 million deaths among 30.3 million participants. BMJ. 2016;353:i2156.

5. Guallar-Castillon P, García EL, Palacios LL, Gutierrez-Fisac J, Banegas JB, Urdinguio PL, Artalejo FR. The relationship of overweight and obesity with subjective health and use of health-care services among Spanish women. Int J Obes. 2002;26(2):247.

6. Reidpath DD, Crawford D, Tilgner L, Gibbons C. Relationship between body mass index and the use of healthcare services in Australia. Obes Res. 2002; 10(6):526-31.

7. Raebel MA, Malone DC, Conner DA, Xu S, Porter JA, Lanty FA. Health services use and health care costs of obese and nonobese individuals. Arch Intern Med. 2004;164(19):2135-40.

8. Von Lengerke T, Happich M, Reitmeir P, John J, Group KS: Utilization of outand inpatient health services by obese adults: a population-based study in the Augsburg region, Germany. Das Gesundheitswesen 2005, 67(S 01):150157.

9. Bertakis KD, Azari R. Obesity and the use of health care services. Obes Res. 2005;13(2):372-9.

10. Peytremann-Bridevaux I, Santos-Eggimann B. Healthcare utilization of overweight and obese Europeans aged 50-79 years. J Public Health. 2007; 15(5):377.

11. Gupta S, Richard L, Forsythe A. The humanistic and economic burden associated with increasing body mass index in the EU5. Diabetes Metab Syndr Obes. 2015:8:327.

12. Elrashidi MY, Jacobson DJ, Sauver JS, Fan C, Lynch BA, Rutten LJF, Ebbert JO. Body mass index trajectories and healthcare utilization in young and middle-aged adults. Medicine. 2016:95(2):e2467.

13. Luchsinger JA, Wn L, Carrasquillo O, Rabinowitz D, Shea S. Body mass index and hospitalization in the elderly. J Am Geriatr Soc. 2003;51(11):1615-20.

14. Allison DB, Zannolli R, Narayan $\mathrm{K}$. The direct health care costs of obesity in the United States. Am J Public Health. 1999;89(8):1194-9.

15. Thompson D, Edelsberg J, Colditz GA, Bird AP, Oster G. Lifetime health and economic consequences of obesity. Arch Intern Med. 1999;159(18):2177-83.

16. Tucker DM, Palmer AJ, Valentine WJ, Roze S, Ray JA. Counting the costs of overweight and obesity: modeling clinical and cost outcomes. Curr Med Res Opin. 2006:22(3):575-86.

17. Lakdawalla DN, Goldman DP, Shang B. The health and cost consequences of obesity among the future elderly. Health Affairs. 2005;24:W5R30.

18. Daviglus ML, Liu K, Yan LL, Pirzada A, Manheim L, Manning W, Garside DB, Wang R, Dyer AR, Greenland P. Relation of body mass index in young adulthood and middle age to Medicare expenditures in older age. Jama. 2004;292(22):2743-9.

19. Finkelstein EA, Trogdon JG, Brown DS, Allaire BT, Dellea PS, Kamal-Bahl SJ. The lifetime medical cost burden of overweight and obesity: implications for obesity prevention. Obesity. 2008;16(8):1843-8.

20. Ng M, Fleming T, Robinson M, Thomson B, Graetz N, Margono C, Mullany EC, Biryukov S, Abbafati C, Abera SF. Global, regional, and national prevalence of overweight and obesity in children and adults during 1980- 
2013: a systematic analysis for the Global Burden of Disease Study 2013. Lancet. 2014;384(9945):766-81.

21. World Health Organization. Obesity (body mass index $\geq 30$ ),agestandardized (\%). 2017. http://www.who.int.

22. Amdam S, Vrålstad S. Levekårsundersøkelsen om helse, omsorg og sosia kontakt 2012. In: Notater 2014/3. Oslo-Kongsvinger: Statistics Norway; 2014.

23. Hougen HC: Samordnet levekårsundersøkelse 2005 tverrsnittsundersøkelsen. In: Notater 2006/39. Statistics Norway; 2006

24. Hougen HC, Gløboden MA. Samordnet levekårsundersøkelse 2002 tverrsnittsundersøkelsen. In: Notater 2004/22: Statistics Norway; 2004

25. Isungset MA, Lunde ES: Levekårsundersøkelsen om helse 2015. In: Notater 2017/9. Oslo - Kongsvinger: Statistics Norway; 2017.

26. Wilhelmsen M: Samordnet levekårsundersøkelse 2008 Tverrsnittsundersøkelsen. In: Notater 2009/40. Statistics Norway; 2009.

27. Kjøllesdal MK, Smith GD, Ariansen I, Kinge JM, Degerud E, Næss Ø. The association between BMI and mortality using early adulthood BMI as an instrumental variable for midlife BMI. Scientific Rep. 2018:8.

28. Statistics Norway. Tabell: 07902: Dødelighetstabeller, etter kjønn og alder. http://www.ssb.no.

29. Trivedi PK. Models for Count Data A2 - Culyer, Anthony J. In: Encyclopedia of Health Economics. San Diego: Elsevier; 2014. p. 306-11.

30. Pohlmeier $W$, Ulrich $V$. An econometric model of the two-part decisionmaking process in the demand for health care. J Human Resources. 1995:339-61

31. Gurmu S. Semi-parametric estimation of hurdle regression models with an application to medicaid utilization. J Appl Econ. 1997:225-42.

32. Partha Deb, Edward C. Norton, Manning WG: Health Econometrics Using Stata: Stata Press; 2017.

33. StataCorp: Stata Statistical Software: Release 14. College Station, TX: StataCorp LP. 2015.

34. R Core Team. R: A Language and Environment for Statistical Computing. Vienna, Austria: R Foundation for Statistical Computing; 2016.

35. Krul AJ, Daanen HA, Choi H. Self-reported and measured weight, height and body mass index (BMI) in Italy, the Netherlands and North America. Eur J Public Health. 2011;21(4):414-9.

36. Kuczmarski MF, Kuczmarski RJ, Najjar M. Effects of Age on Validity of SelfReported Height, Weight, and Body Mass Index: Findings from the Third National Health and Nutrition Examination Survey, 1988-1994. J Am Dietetic Assoc. 2001;101(1):28-34.

37. Ritter PL, Stewart AL, Kaymaz H, Sobel DS, Block DA, Lorig KR. Self-reports of health care utilization compared to provider records. J Clin Epidemiol. 2001; 54(2):136-41.

38. Jiménez-Martín S, Labeaga JM, Martínez-Granado M. Latent class versus two-part models in the demand for physician services across the European Union. Health Econ. 2002;11(4):301-21.

39. Deb P, Trivedi PK. The structure of demand for health care: latent class versus two-part models. J Health Econ. 2002;21 (4):601-25.

40. Simmonds M, Llewellyn A, Owen C, Woolacott N. Predicting adult obesity from childhood obesity: a systematic review and meta-analysis. Obes Rev. 2016;17(2):95-107.

41. Rokholm B, Baker JL, Sørensen TIA. The levelling off of the obesity epidemic since the year 1999-a review of evidence and perspectives. Obes Rev. 2010; 11(12):835-46.

42. Kelly T, Yang W, Chen CS, Reynolds K, He J. Global burden of obesity in 2005 and projections to 2030. Int J Obes. 2008;32(9):1431-7.

43. Katzmarzyk PT, Janssen I. The economic costs associated with physical inactivity and obesity in Canada: an update. Can J Appl Physiol. 2004;29(1):90-115.

44. Locke AE, Kahali B, Berndt SI, Justice AE, Pers TH, Day FR, Powell C, Vedantam S, Buchkovich ML, Yang J. Genetic studies of body mass index yield new insights for obesity biology. Nature. 2015;518(7538):197-206.

45. Schafer MH, Ferraro KF. Obesity and hospitalization over the adult life course: does duration of exposure increase use? J Health Soc Behav. 2007; 48(4):434-49.

46. Cawley J, Meyerhoefer C, Biener A, Hammer M, Wintfeld N. Savings in medical expenditures associated with reductions in body mass index among US adults with obesity, by diabetes status. Pharmacoeconomics. 2015;33(7):707-22.

\section{Publisher's Note}

Springer Nature remains neutral with regard to jurisdictional claims in published maps and institutional affiliations.

Ready to submit your research? Choose BMC and benefit from:

- fast, convenient online submission

- thorough peer review by experienced researchers in your field

- rapid publication on acceptance

- support for research data, including large and complex data types

- gold Open Access which fosters wider collaboration and increased citations

- maximum visibility for your research: over $100 \mathrm{M}$ website views per year

At BMC, research is always in progress.

Learn more biomedcentral.com/submissions 